\title{
A fundação da "cidade-capitania" do Rio de Janeiro e a Repartição do Sul: notas sobre administração colonial
}

Fabiano Vilaça dos Santos*

\begin{abstract}
Resumo
O presente artigo aborda a polêmica sobre a fundação da cidade de São Sebastião do Rio de Janeiro, em 1565/67, associada à criação da capitania real do Rio de Janeiro. O trabalho contempla, ainda, a análise da adoção e do funcionamento de uma divisão administrativa que alterou por três vezes a configuração política e jurisdicional do governo-geral do Estado do Brasil, originalmente instalado na Bahia: a Repartição do Sul, sediada no Rio de Janeiro nos séculos XVI e XVII.
\end{abstract}

Palavras-chave: Cidade do Rio de Janeiro; Capitania Real do Rio de Janeiro; Repartição do Sul; Administração colonial.

\begin{abstract}
This article discusses the controversy over the founding of the city of Sao Sebastião do Rio de Janeiro, in 1565/67 associated with the creation of real captaincy of Rio de Janeiro. The work also includes the analysis of the adoption and operation of an administrative division which has changed three times political and jurisdiction setting government-general of the State of Brazil, originally installed in Bahia: the South Section, based in Rio de Janeiro in the sixteenth and seventeenth centuries.
\end{abstract}

Keywords: The Rio de Janeiro City; Royal Captaincy of Rio de Janeiro; South Section; Colonial administration. 


\section{Introdução}

O estudo da história administrativa do Rio de Janeiro no século XVI conduz a uma inevitável conclusão: entre os anos de 1565 e 1567 houve o entrelaçamento da fundação da urbe, colocada desde os primórdios sob a proteção de São Sebastião, e da capitania real do Rio de Janeiro. Ambas têm algo em comum: a origem em terras da capitania de São Vicente, doada em 1534 a Martim Afonso de Sousa.

Nos anos que se seguiram, o donatário dedicou-se a fomentar a produção açucareira em São Vicente, havendo pouca presença de colonos ao norte da capitania, justamente onde vicejava o contrabando de pau-brasil pelos franceses aliados aos índios. Segundo Armelle Enders, as capitanias de São Vicente e do Espírito Santo, ao sul, eram mais frequentadas por corsários estrangeiros do que a costa norte. Esse fato está na raiz da comunicação feita em 1548 por Luís de Góis, irmão do capitão-mor Pero de Góis, a D. João III, afirmando que o monarca perderia aquelas capitanias, caso não as socorresse. A criação do governogeral teria sido, entre outros aspectos, uma resposta a tal situação. Para Armelle Enders, a medida não foi suficiente para afastar a ameaça estrangeira, que se tornou mais crítica com o estabelecimento de uma colônia francesa na Baía da Guanabara por Nicolas Durand de Villegagnon: a França Antártica (1555-1560). A fundação da cidade do Rio de Janeiro estava inserida nesse contexto de disputa entre monarquias europeias pela costa americana (Enders, 2008:22-36).

Contudo, a efeméride celebrada em $1^{\circ}$ de março de 2015 tem outro apelo: urge que se faça uma revisão historiográfica sobre a fundação do Rio de Janeiro, englobando o período inicial de sua constituição como cidade, dotada de instituições e de uma estrutura governativa, um dos aspectos mais complexos dessa relação entre a cidade e a capitania. Essas notas, longe de esgotarem o tema, têm o objetivo de discutir alguns aspectos da administração da capitania, com ênfase no governo e nas questões jurisdicionais. O artigo percorrerá cerca de um século: da fundação da cidade e da capitania, em 1565/67, ao fim da última experiência da Repartição do Sul, em 1662.

\section{A cidade e a capitania real do Rio de Janeiro (século XVI)}

A fundação da cidade do Rio de Janeiro é assunto controvertido. O $1^{\circ}$ de março de 1565 consagrado pela tradição é também uma construção histórica que se revela no exame de crônicas da colonização portuguesa e no discurso de autores clássicos. Eles sinalizam para a vertente religiosa de que se revestiu a conquista da Guanabara e para o ato políticoadministrativo de fundação da cidade. Desponta, ainda, outra questão: a empresa deve ser creditada ao governador-geral Mem de Sá ou a seu sobrinho, Estácio de Sá?

Em Memórias da cidade do Rio de Janeiro, Vivaldo Coaracy (1882-1967) afirmou que o evento se deu a $1^{\circ}$ de março de 1565, por iniciativa de Estácio de Sá, portanto, "é erro crasso que não encontra nenhuma base histórica querer atribuí-la [...] a Mem de Sá no dia 20 de janeiro de 1567, que é apenas a data do início dos combates finais contra os remanescentes dos franceses”. Estácio de Sá teria dotado a cidade de instituições, como a Câmara, erguido uma igreja, estabelecido o termo e o rossio e concedido sesmarias aos primeiros povoadores e aos jesuítas. Entre a sua morte e a nomeação de Salvador Correia de Sá, o velho (1568-1571), o Rio de Janeiro teria ficado sob a autoridade de Mem de Sá (Coaracy, 1955:538-542).

6 - Cadernos do Desenvolvimento Fluminense, Rio de Janeiro, N.7, pp. 5 - 20, jan./jun. 2015 
Criticada por Coaracy, a hipótese da fundação em 1567 foi sustentada por Mecenas Dourado (1893-1967). Segundo este autor, "é uma simplificação deformadora da realidade dizer que a cidade do Rio de Janeiro foi fundada a $1^{\circ}$ de março de 1565 ”. A data assinalava a chegada de Estácio de Sá à região do Morro Cara de Cão para combater os franceses aliados aos tamoios. Além de não haver qualquer diploma legal que ratificasse a fundação, "o primeiro ato" do sobrinho do governador-geral "que indicava intenção de dar fisionomia política à povoação", "a concessão do seu patrimônio territorial”, ocorreu somente em 16 de julho de 1565. Coube a Mem de Sá, conquanto não houvesse em seu Regimento (1557) nenhum dispositivo que previsse a construção de uma cidade na Baía da Guanabara, a definição do seu termo, em 16 de agosto de 1567, oficializando o ato da fundação (Dourado, 1965:7-29).

Embora tenha realçado a participação dos jesuítas nesse processo citando uma carta de 1560 do padre Manuel da Nóbrega ao infante D. Henrique, em que o missionário afirmava "ser necessário povoar-se o Rio de Janeiro e fazer-se nele outra cidade como a da Bahia, porque com ela ficaria tudo guardado, assim esta capitania de São Vicente como a do Espírito Santo" (Dourado, 1965:23), Mecenas Dourado aparentemente não se deu conta de que as ideias de Nóbrega já haviam chegado a Lisboa. Não por intermédio dos jesuítas, mas pela pena do próprio Mem de Sá. Em uma carta de $1^{\circ}$ de junho de 1558, endereçada à regente D. Catarina, manifestou o propósito de fundar uma cidade ao norte de São Vicente "e me parece que com a ajuda de Deus que em pouco tempo a hei de fazer tal como esta do Salvador, a outra será do Espírito Santo: assim segurar-se-á a terra de todo do gentio, e dos franceses [...]” (Serrão, 1965:34, vol. II).

Pouca ou nenhuma atenção é dada a essa carta. Confrontando-a com certos argumentos de Mecenas Dourado, pode-se concluir que, se o Regimento de Mem de Sá não previa a criação de uma povoação na Guanabara, reflexões posteriores baseadas no mau aproveitamento das donatarias do Espírito Santo e de São Tomé e na ocupação francesa - a França Antártica levaram a uma mudança de orientação. Se nesse período, "por absoluta falta de recursos o governo da Bahia não importunou” os invasores, isso não quer dizer que Mem de Sá não pensasse em uma estratégia para assegurar o domínio português sobre a área ocupada. Isso explicaria a expedição de Estácio de Sá, que deixou Portugal em 1563 e depois de percorrer Espírito Santo e São Vicente para arregimentar combatentes, chegou ao Rio de Janeiro e fundou a cidade em $1^{\circ}$ de março de 1565 (Wehling e Wehling, 2005:72-73).

Nessa perspectiva, o mérito foi de Estácio de Sá, porém, entre 1565 e 1567 a consolidação do projeto ficou a cargo de seu tio. Durante sua permanência no Rio de Janeiro, o governadorgeral mandou cercar a nova cidade de muros e provê-la de baluartes para defesa, ordenou a construção da Sé, da casa da Câmara, de uma cadeia e de um armazém para os apetrechos da Fazenda. Teria, então, dado o primeiro impulso à organização política da urbe (Serrão, 1965:122, vol. I). É possível constatar que os mesmos elementos ressaltados por Joaquim Veríssimo Serrão e por Arno e Maria José Wehling estão na base dos argumentos de Mecenas Dourado, para quem tocou a Mem de Sá a inciativa de conferir à povoação rústica erguida em 1565 os traços de uma cidade.

As interpretações mencionadas, assim como outros escritos sobre a ocupação e a conquista da Guanabara, enfatizam o belicismo e a necessidade de defesa de um projeto colonizador que começou a ser gestado na América portuguesa pouco antes de 1550. Essas visões estão respaldadas em modelos interpretativos do século XIX, momento fundador de uma historiografia brasileira, como salientou Paulo Knauss: 
[...] o discurso histórico acerca da presença portuguesa na América no século XVI está enformado pela historiografia do século XIX. Possivelmente, não seria demasiado afirmar que essa perspectiva inaugurada no século passado se viu aprofundada com a consagração do tema reunido em redor da expressão invasão estrangeira, englobando genericamente todas as tentativas de presença no território da América portuguesa por elementos não lusitanos. Perde-se, assim, de vista a totalidade do sistema histórico e no qual europeus se igualam, na medida em que são autores do movimento de Expansão Marítima e Comercial. (Knauss de Mendonça, 1991:41, grifos do autor)

Trata-se de uma herança que procurou valorizar e defender os interesses portugueses, perturbados por invasores e pela "ferocidade" dos índios, polarizados em aliados e inimigos, sem levar em conta a dinâmica da expansão marítima e a concorrência entre os países envolvidos nesse processo. Francisco Adolfo de Varnhagen faz parte dessa matriz interpretativa. Sua História Geral do Brasil (1854-1857), além de se apresentar como uma “continuação da história da metrópole”, entrou em choque com a corrente indianista do Romantismo brasileiro pelo modo desfavorável como abordou os nativos da América (Guimarães, 2001:79 e 94-96, vol. 2).

Nos últimos anos, a vertente interpretativa em que investiu Maria Regina Celestino de Almeida procurou rever a posição dos índios no sistema de construção de alianças com os portugueses e os franceses. Segundo a historiadora, os tamoios, temiminós e tupiniquins, pertencentes ao tronco tupi, oriundos de São Vicente e do Espírito Santo, participaram “intensamente nas guerras no Rio de Janeiro”. Esses índios construíram alianças com os europeus em concorrência no litoral do Atlântico Sul. Como assinalou Maria Regina Celestino, “abandonada nas primeiras décadas da colonização, a baía de Guanabara tornara-se reduto antilusitano, onde os tamoios aliados aos franceses não apenas impediam o estabelecimento português na região, como ameaçavam as capitanias de São Vicente e do Espírito Santo" (Almeida, 2003:49 e 68).

Os modelos interpretativos do século XIX, por sua vez, são tributários das crônicas do período colonial, em que os elementos míticos e históricos se mesclam no relato dos acontecimentos. Nem sempre é fácil determinar a matriz original de tal ou qual interpretação. Uma delas é, sem dúvida, a História do Brasil, de Frei Vicente do Salvador (1627), para quem o santo que deu nome à cidade foi o fiador do sucesso português em 1565, "pois a vitória [...] se ganhou [no] dia de São Sebastião e em este dia, dois anos antes, partiu Estácio de Sá de São Vicente para o Rio de Janeiro, e começou a guerra invocando o seu favor, o qual reconheceram bem os portugueses, assim na batalha naval das canoas, como em outras ocasiões de perigo" (Salvador, 2008:130-131).

A narrativa do franciscano conjuga elementos míticos e históricos: "O sítio em que Mem de Sá fundou a cidade de São Sebastião do Rio de Janeiro foi o cume de um monte, donde facilmente se podiam defender dos inimigos [...]" (Salvador, 2008:131). Embora a cronologia não seja clara, é perceptível no discurso de Frei Vicente que os eventos se sucederam entre a chegada de Estácio de Sá, a vitória dos portugueses e seus aliados índios e o estabelecimento da urbe.

A crônica de Sebastião da Rocha Pita se mostrou mais comedida no relato das lutas portuguesas. Mas a combinação de forças sobrenaturais e militares também aparece na História da América portuguesa (1730). Nos reforços enviados da Bahia por Mem de Sá, o espiritual e o temporal estavam representados, respectivamente, pelo bispo D. Pedro Leitão (1558-1574) e pelo governador-geral. Um traço típico da escrita de Rocha Pita, que elegeu como "protagonistas” da história da colonização “a Coroa, a Igreja, as instituições 
portuguesas, as autoridades em geral [...]" (Neves, 2000). Desse modo, “os cabos, soldados e aventureiros iam alegres, vendo-se assistidos de duas fortíssimas colunas, uma da Igreja, outra da monarquia, entendendo que nos apertos da vida teriam capitão para os animar, e nos transes da morte prelado para os absolver" (Pita, 1976:86).

Independentemente de quem foi o responsável pela fundação e pelo estabelecimento das primeiras instituições, ou de quando isso ocorreu, sem dúvida, os portugueses tinham noção do valor estratégico das bases lançadas naquelas terras:

\footnotetext{
O local permitia a instalação de um excelente porto, fundamental para o comércio atlântico; suas características geográficas facilitavam a defesa contra ataques estrangeiros; sua estratégica situação tornava possível o controle da extensa orla marítima que ia daquele ponto até o extremo sul da costa, além de permitir a interiorização do continente, em busca de metais e pedras preciosas. (Cavalcanti, 2004:22)
}

Aos aspectos políticos e militares, à posição geográfica do Recôncavo da Guanabara e à crença no seu potencial em termos de riquezas, deve ser acrescentada outra justificativa para o esforço português de conquista, revelada por João Fragoso: “[...] o passo seguinte seria viabilizar a economia de plantations aproveitando assim o trend de alta do açúcar" (Fragoso, 2000:67).

Sobre o que era a capitania real do Rio de Janeiro, fundada segundo consta em 4 de março de 1567 (Salgado, 1990:416), na ocasião dos últimos combates entre as forças portuguesas e francesas, persiste a imprecisão. O Tratado da Terra do Brasil, de Pero de Magalhães Gandavo, traz um capítulo intitulado “Da capitania do Rio de Janeiro”, em que se diz: "A capitania do Rio de Janeiro cidade de São Sebastião está sessenta léguas do Espírito Santo em vinte e três graus e um terço, terra d' El Rei nosso senhor". Destacou ainda sua fertilidade e a abundância de "águas para engenhos de açúcar" (Gandavo, 2008:47). A crítica historiográfica atribuiu à obra a aparência de "um texto de propaganda da nova terra", em uma época na qual "o país apenas começava, era mal conhecido". ${ }^{1}$

\section{Dividir para governar: a Repartição do Sul (séculos XVI e XVII)}

Com o retorno de Mem de Sá à Bahia após a expulsão dos franceses em 1567, Salvador Correia de Sá, o velho, assumiu pela primeira vez o governo da capitania do Rio de Janeiro (1568-1572). Foi sucedido por Cristóvão de Barros (1572-1574), “companheiro de Estácio de Sá na conquista da terra” (Coaracy, 1955:542-543). A carta régia que o nomeou é interessante por mencionar que viria como capitão-mor da "Capitania e Cidade de São Sebastião do Rio de Janeiro", por quatro anos. ${ }^{2}$

O português Cristóvão de Barros não foi somente um dos combatentes no Recôncavo da Guanabara. Suas atividades militares, o trato com os índios e o seu envolvimento na ocupação produtiva do território atestam as múltiplas facetas de um dos pioneiros na ocupação da terra. Filho de Antônio Cardoso de Barros, primeiro provedor-mor da Fazenda do Brasil, comandou a frota que veio do Reino a pedido de Mem de Sá para socorrer o Rio de

1 Cf. Iglésias (2000:27-28). Segundo Capistrano de Abreu, por ter sido escrito antes de 1573, o Tratado da Terra do Brasil não menciona a divisão em dois governos, ao contrário do que Gandavo fez posteriormente na História da província de Santa Cruz, a que vulgarmente chamamos Brasil. Cf. Gandavo (2008:20).

2 Arquivo Nacional da Torre do Tombo [ANTT]. Chancelaria de D. Sebastião e D. Henrique. Livro 27, fls. 329v-330; Chancelaria de D. Sebastião e D. Henrique - Doações, Ofícios, Mercês etc. Livro 38, fl. 155v. Provisão para o cargo de provedor-mor da Fazenda do Brasil. Ver também Serrão (1965:86, vol. II). 
Janeiro, recebendo terras a título de sesmarias em Magé e no sertão do rio Macacu. ${ }^{3}$ A razão de sua indicação para a governança não estaria ligada apenas ao seu papel de conquistador, mas à concretização de um projeto de povoamento e de colonização do Brasil, idealizado no reinado de D. Sebastião e colocado sob a responsabilidade de Mem de Sá. As crônicas e a historiografia tradicional realçam o perfil belicoso e a operosidade de Cristóvão de Barros (Cf. Serrão, 2004:322; Salvador, 2008:144).

A morte de Mem de Sá, em março de 1572, despertou incertezas em Lisboa sobre a continuidade dos projetos de colonização em andamento e levou à adoção de um novo sistema administrativo para a colônia: a Repartição do Sul, com sede na capitania do Rio de Janeiro:

Quando a corte tomou conhecimento da morte de Mem de Sá, decidiu o monarca assentar uma nova política no governo do Brasil [...]. A defesa da costa contra o ataque dos corsários, a política religiosa de assimilação dos nativos e a necessidade de impor a autoridade do poder central mostraram ao monarca as vantagens de uma divisão na tarefa do governo do Brasil. (Serrão, 1965:140, vol. I)

Tema pouco aprofundado pela historiografia e alvo de muitas controvérsias, segundo Mônica da Silva Ribeiro, não há sequer um consenso sobre as ocasiões em que Repartição do Sul foi implantada. ${ }^{4} \mathrm{~A}$ análise dessa divisão administrativa seguirá a indicação da historiadora de que ela vigorou em três momentos (de 1572 a 1577, de 1608 a 1612 e de 1658 a 1662) atentando-se para as especificidades de cada um (Ribeiro, 2006:1).

A Repartição do Sul (1572-1577) surgiu no tempo em que Cristóvão de Barros era capitão-mor da cidade do Rio de Janeiro. A data oficial coincidiu com a nomeação de Luís de Brito e Almeida (governador na Bahia) e Antônio Salema (governador da Repartição do Sul). ${ }^{5}$ A carta régia que nomeou Luís de Brito (por seis anos) informa que a separação dos governos pretendia evitar os danos à Justiça e à Fazenda pelo fato de as partes do Brasil estarem "tão distantes umas das outras". ${ }^{6}$ A Repartição do Sul abrangeu as capitanias do Rio de Janeiro, do Espírito Santo e de São Vicente, enquanto as do norte ficaram sujeitas à Bahia.

Na historiografia, há diversas justificativas para a medida, mas todas apontaram a defesa como o principal objetivo. Frei Vicente do Salvador deixou registrado que a Luís de Brito e Almeida coube, por exemplo, erguer uma povoação fortificada no Rio da Paraíba de modo a afastar a ameaça dos franceses e dos potiguares. Antônio Salema combateu o contrabando de pau-brasil entre franceses e tamoios, em Cabo Frio, com o apoio do capitão-mor Cristóvão de Barros (aí fica claro que sua jurisdição se limitava à cidade do Rio de Janeiro) e mais "400 portugueses e 700 gentios amigos". ${ }^{7}$

Mas, no tempo de Salema, a estruturação administrativa da capitania também prosseguiu, com a criação de uma prelazia (1575) independente do bispado da Bahia,

3 Serrão, 1965:137, vol. I. Segundo Frei Vicente do Salvador, Cristóvão de Barros era filho bastardo. Cf. História do Brazil, p. $143-144$.

4 Ribeiro (2006:1-9. Disponível em: www.rj.anpuh.org. Acesso em: 07/02/2014). 0 trabalho é referência atualizada sobre 0 assunto. Segundo Arno Wehling (1994), a Repartição do Sul foi adotada duas vezes: de 1574 a 1578 e de 1608 a 1612. Da mesma forma se referiu Gouvêa (2000).

5 Cf. Salgado (1990:416-417). Antônio Salema (também denominado "de Salema”) já estava na América para averiguar a situação política e administrativa das capitanias do norte. Natural de Alcácer do Sal, formou-se em Leis na Universidade de Coimbra. Desembargador da Casa da Suplicação por carta régia de 02/03/1570, começou a servir na Bahia e esteve em Pernambuco entre 1571 e 1573 . De volta ao Reino, foi desembargador dos Agravos em 1583 e faleceu em 13 de março de 1586 (Cf. Serrão, 1965:136). A carta de desembargador da Casa da Suplicação de Lisboa encontra-se no ANTT. Chancelaria de D. Sebastião e D. Henrique. Livro 25, fl. 11.

6 ANTT. Chancelaria de D. Sebastião e D. Henrique. Livro 29, fls. 111v-112v. Carta régia de 10/12/1572.

7 Salvador (2008:153-154). Citando Joaquim Veríssimo Serrão, Francisco Iglésias mencionou que o cronista franciscano teria consultado uma História do Brasil, de Antônio Salema, "cujos originais se perderam” (Iglésias, 2000:29). Ver também Pinheiro (1859:64); Coaracy (1955:543). 
com jurisdição sobre as capitanias de São Vicente, Espírito Santo, além do Rio de Janeiro. ${ }^{8}$ Aparentemente, a medida não serviu apenas para garantir assistência espiritual aos moradores e subsidiar o trabalho de conversão dos índios à fé católica. Para Américo Jacobina Lacombe, a fundação da prelazia revestiu-se de uma função moralizadora, atalhando a relaxação dos costumes e a escravidão ilegal dos nativos (Lacombe, 1967:38-39, vol. 276 ) - referência indireta ao alvará de 20 de março de 1570 que regulava o cativeiro indígena.

Juízos à parte, "com a chegada do novo governador [Antônio Salema], o Rio de Janeiro aumentava de importância no conjunto da terra do Brasil, por servir de assento à autoridade máxima das capitanias do Sul” (Serrão, 1965:141, vol I). A conclusão de Joaquim Veríssimo Serrão evidencia um aspecto crucial: a posição central do Rio de Janeiro no sistema colonial, inclusive para os contatos comerciais com a bacia platina, expandidos com a União Ibérica (1580-1640). Em outra obra, o historiador português ofereceu uma interessante justificativa para o insucesso da Repartição do Sul, que durou praticamente os seis anos previstos na carta régia de 1572. De acordo com Serrão, à época da divisão, as capitanias de baixo representavam "uma parcela essencial no desenvolvimento do Brasil, dada não somente a proximidade da América espanhola, como também o comércio cada vez mais intenso que Angola, São Tomé e Cabo Verde [...] vão fazer com as partes meridionais do Brasil”. E continuou: "Esse abraço das duas zonas [norte e sul] fortaleceu-se com a ação de Mem de Sá”, de modo que a separação do governo do Brasil "em duas 'bandas' [...] não pôde resultar e foi revogada em 1577”. ${ }^{9} \mathrm{Ou}$ seja, a experiência atingira justamente a "unidade" ou a centralidade do governo-geral. Essa perspectiva é importante, pois foi reiterada tanto por autoridades coloniais quanto por outros historiadores.

Em termos gerais, a conjuntura do final do século XVI e do início da centúria seguinte caracterizou-se pela persistência da preocupação defensiva por parte da Coroa, pelo avanço do comércio entre o Rio de Janeiro e a região platina (vide a ação dos peruleiros) e pela intensificação da busca de minas. Por outro lado, como sintetizou Mônica Ribeiro (2006:4), "o período da União Ibérica teve grande importância em termos da intensificação de experimentações quanto a melhor se dividir, administrar e governar a América portuguesa”.

Sem querer esmiuçar um tema (a mineração) que conta com uma vasta e atualizada produção historiográfica, é válido pontuar aspectos de uma atividade intimamente ligada à organização político-administrativa da capitania Rio de Janeiro. João Antonio de Paula fala de "algo semelhante a uma pré-história" dos achados auríferos que, apesar das "controvérsias, a historiografia localiza no final do Quinhentos. Trata-se dos descobertos do século XVI, consequência das expedições que ganharam o sertão mineiro em busca do metal amarelo, partindo da Bahia”. Para o autor, há forte tendência na historiografia em aceitar que os primeiros descobrimentos de ouro em Minas aconteceram na última década

8 Instituto Histórico e Geográfico Brasileiro [IHGB]. Lata 55, doc. 16. Pelo breve Novi Orbis, do papa Gregório XIII, de 19/07/1576, houve 0 desmembramento da "igreja do Rio de Janeiro do bispado da Bahia", cujo titular exerceria "as suas funções em todas as vilas, e lugares sujeitos ao Governo do Rio de Janeiro com plena jurisdição, independentemente de qualquer outra aprovação" (fls. 25-26). Outros autores se referem à criação da prelazia pela Bula In supereminenti militantis ecclesiae, de 19/07/1575. Ver Salgado (1990:116). Nesta obra afirma-se que a capitania de Porto Seguro pertencia à jurisdição da prelazia do Rio de Janeiro.

9 Serrão (2004:322-323). É de estranhar que 0 autor sequer mencione a experiência da Repartição Sul no período ao qual seu livro se dedica, quiçá por se preocupar mais com os impactos da União Ibérica no Brasil no que se refere às invasões holandesas (p. 323ss). 
daquela centúria, malgrado a inexatidão sobre quem os realizou a localização dos veios (Paula, 2007:279-282, vol. 1). Júnia Furtado diz que "desde pelo menos a segunda metade do século XVI houve notícias esparsas de que os diamantes se encontravam entre as riquezas do Brasil”. E "foi durante a União Ibérica (1580-1640) que se intensificou a busca por metais e pedras preciosas no interior", mobilizando homens como D. Francisco de Sousa (Furtado, 2007:303, vol. 1).

O nobre de boa linhagem, filho do $1^{\circ}$ conde do Prado, D. Pedro de Sousa, e sobrinho de um bispo do Algarve, D. Manuel de Sousa (1538-1545) (Cf. Paiva, 2006:308 ), foi designado para governar as partes do sul. Desde a época em que exercia o governo-geral (1591-1602) acalentava a ideia de encontrar riquezas minerais. Nos idos de 1592, de acordo com José Carlos Vilardaga, D. Francisco de Sousa instalou-se com armas e bagagens na vila de São Paulo de Piratininga. E “conseguiria, ao longo da última década do século XVI e da primeira do século XVII, manter acesa, nas imaginações da Corte espanhola, a chama da sonhada riqueza mineral em territórios da América portuguesa [...]”. ${ }^{10}$

D. Francisco de Sousa foi encarregado da Repartição do Sul em 2 de março de 1608, "com total autonomia", a fim de descobrir minas, fortificar os portos e evitar as ameaças estrangeiras (Lacombe, 1967:29). Arribou em Pernambuco na companhia dos filhos, dispensando o governador-geral, D. Diogo de Meneses (1608-1612), da homenagem que este fizera sobre as fortalezas do Espírito Santo, Rio de Janeiro e São Vicente, "porquanto o [sic] fazia governador delas com os mesmos poderes que eu [D. Diogo de Meneses] nelas tinha e assim mais o fazia superintendente das minas que houvesse neste distrito e das mais que houver em todo este Estado". ${ }^{11}$

O espanto com que D. Diogo recebeu a novidade toca mais uma vez na questão da centralidade do cargo que ocupava. Em 1608, o próprio governador-geral sentiu-se atingindo pela diminuição de seu poder, repartido com D. Francisco de Sousa. Contrariado, tomou a liberdade de dizer ao rei o que pensava da separação dos governos: “[...] o mesmo negócio há de mostrar cedo a Vossa Majestade a perda que há de ter sua Fazenda ou a utilidade, mas terá um mal que o perdido não se poderá recuperar”. À alegação de que a arrecadação fiscal seria afetada somou-se o sentimento de desonra pela decisão régia:

\footnotetext{
Foi o agravo que Vossa Majestade me fez nesta separação tão entendido de todos, e de qualidade que por mostrar o entendo assim não pude dissimular, [...] mas espero na clemência e grandeza de Vossa Majestade o remedeie e me faça as mercês que lhe mereço restituindo-me minha honra do modo que Vossa Majestade ordenar e lhe parecer [...]. Vossa Majestade me mandou o viesse servir a este Estado sem me declarar nenhuma separação, se não que eu o viria governar assim e da maneira que os passados, onde o tenho servido com toda a fidelidade e satisfação [...]. (IDEM, fls. 64v-65v )
}

A ofensa à honra pessoal protestada por um homem do Antigo Regime dissimulava a inconveniência da divisão de poderes com o governador das capitanias do Sul. Havia, ainda, o agravante de D. Francisco de Sousa acumular a superintendência das minas e D. Diogo de Meneses prever desordens na administração sediada no Rio de Janeiro, além de conflitos de jurisdição causados por eventuais descobrimentos:

[...] para cada mina é necessário uma pessoa que a governe, e sendo caso que se ache uma mina no meu distrito como poderá ele [...] governar sendo forçado que há de deixar a de ouro de São Vicente que ele diz tem tanto

10 Vilardaga (2013:796-797). Em outubro de 1598, teria D. Francisco de Sousa deixado novamente a Bahia em direção ao sul à procura de metais, alcançando mais tarde 0 Rio de Janeiro (IHGB. Lata 36, doc. 13).

11 IHGB. Seção do Conselho Ultramarino. Arq. 1. 3. 10, fls. 63v-72. Carta de D. Diogo de Meneses, governador do Brasil, escrita da Bahia a El Rei D. Filipe $2^{0} \ldots$ Lisboa, 22 de abril de 1609. Citação à fl. 64. 
e cedo se verá o que manda a Fazenda de Vossa Majestade que são trezentas léguas de uma a outra e assim se vem meter no meu distrito, deixando o seu desamparado de governo, e sem lhe poder acudir no necessário de inimigos que continuadamente andam naquela costa, e como esta está ainda tão despovoada, é necessário ele meter-se na terra dentro onde as minas devem estar, e aonde não tem mantimentos nem com que se sustentar o pedir ele isto não foi senão descarga de que se quer valer com Vossa Majestade. ${ }^{12}$

A postura de D. Diogo em relação às minas tem outra explicação. Em artigo recente, José Carlos Vilardaga aludiu ao governo-geral de D. Francisco de Sousa (1591-1602):

\begin{abstract}
Essa riqueza mineral, muitas vezes vista como quimera, fomentou uma imagem de certa irresponsabilidade do governador-geral do Brasil, pois este abandonara as cada vez mais ricas regiões açucareiras do Nordeste, ainda vulneráveis aos assédios de outras potências europeias, em detrimento de uma especulada fortuna mineral. Os governadores gerais subsequentes, em especial Diogo Botelho e Diogo de Meneses, fariam questão de ressaltar tal atitude. (Vilardaga, 2013:797)
\end{abstract}

A passagem acima ilumina as palavras de D. Diogo de Meneses. Uma de suas preocupações era justamente não passar à Corte de Madri a imagem de uma gestão displicente, dado o caráter aventureiro atribuído às ações de D. Francisco para encontrar metais preciosos. Seguindo o raciocínio de Vilardaga, D. Diogo não desejava repetir os erros do antecessor.

A celeuma continuou no Rio de Janeiro. À época, Afonso de Albuquerque (1608-1614) era capitão-mor da cidade e servia-se do Regimento e das provisões passadas ao governadorgeral Diogo Botelho (1602-1607), dado o fato de a "capitania do Rio de Janeiro estar muito distante da capitania da Bahia”. ${ }^{13}$ A concentração de poderes foi percebida por Frei Vicente do Salvador que, ironicamente, disparou: "Dali [de Pernambuco] se foi [D. Francisco] para o Rio de Janeiro e começou a entender no seu governo da terra, e o filho no mar, onde dizia Afonso de Albuquerque, que então ali era capitão-mor, que lhe ficava para governar senão o ar" (Salvador, 2008:257-258).

Além da mineração, não pode ser esquecido o comércio entre as capitanias do Sul e o Rio da Prata. ${ }^{14}$ Durante a união das Coroas ibéricas, cresceu o fluxo de africanos escravizados para o Brasil (e para Buenos Aires) a reboque do desenvolvimento da produção açucareira. Em termos gerais, a já referida economia de plantation instalada no Recôncavo da Guanabara permitiu a consolidação do Rio de Janeiro no cenário atlântico. ${ }^{15}$

A Repartição durou aproximadamente o tempo da divisão anterior. Fracassou, segundo os relatos mais conhecidos, devido à frustração das autoridades e da Coroa diante do resultado pífio dos descobrimentos minerais. A morte de D. Francisco de Sousa em São Paulo (1611) teria colaborado para desmontar o esquema da Repartição do Sul. ${ }^{16}$ Outro fator pode ser associado ao retorno da centralização do governo-geral na Bahia. Enquanto as atenções de Madri se concentravam no Sul desde o final do século XVI, por conta da expansão do comércio e da procura de minas, um projeto de colonização do Maranhão vinha sendo cuidadosamente urdido por homens práticos na guerra e na navegação, por meio de contratos com os reis franceses e contando com a participação de missionários capuchinhos: a França Equinocial (1612-1615) (Cf. Daher, 2007:47-73. Citação à página 48).

12 IHGB. Seção do Conselho Ultramarino. Arq. 1. 3. 10, fls. 65v-66.

13 ANTT. Chancelaria de D. Filipe II. Livro 17, fl. 67v. A carta patente de 12/02/1605 cita "Diogo Coelho" como governador-geral do Brasil. Entretanto o correto é Diogo Botelho (1602-1607). Cf. Cosentino (2009:243). Vivaldo Coaracy registrou sobre Afonso de Albuquerque: "Embora desde 1605 houvesse obtido em Lisboa a nomeação para o cargo, só em 1608 apresentou-se [...] para assumir o governo" (Coaracy, 1955:545).

14 Cf. Sanches (2005:105-146). Sobre 0 aumento do fluxo de escravos ver Lobo (1978:20, vol. 1).

15 Para essa questão ver Cavalcanti (2004:22).

16 Cf. Coaracy (1944:33-34). Ver também Sanches (2005:122). 
Para concluir a análise desse segundo período de mudança na estrutura administrativa do Estado do Brasil, vale citar Ambrósio Fernandes Brandão, que em 1618 se referiu à capitania e à cidade do Rio de Janeiro de maneira distinta:

\begin{abstract}
Adiante da capitania do Espírito Santo, para parte do Sul, está a do Rio de Janeiro [...]. É de Sua Majestade, aonde tem uma galharda fortaleza bem abastecida de artilharia, munições, e soldados, e um capitão posto por ele de três em três anos; tem uma cidade posto que pequena, bem situada, a qual é de presente de grande comércio; porque vem a ela muitas embarcações do Rio da Prata, que trazem riqueza muita em patacas; donde tornam a fazer viagem para o mesmo rio. Também neste Rio de Janeiro tomam porto as naus que navegam do Reino para Angola, aonde carregam de farinha da terra, de que abunda toda esta capitania [...] e dali a levam para Angola [...]. Tem alguns engenhos em que se lavram açúcares, e estes anos passados foi cabeça de governo e sede do governador: porquanto apartou Sua Majestade, governando o Brasil D. Diogo de Meneses, três capitanias a saber: a do Espírito Santo, e esta do Rio de Janeiro e a de São Vicente, e as incorporou em um novo governo, de que fez governador D. Francisco de Sousa, a título de descobrir as minas de ouro de São Vicente [...]. E com sua morte se atalharam estas esperanças, que não eram pequenas. (Brandão, 1930:61-62)
\end{abstract}

Apesar de extenso, o diálogo entre Alviano e Brandônio sobre o Rio de Janeiro sintetiza muitos traços da cidade e da capitania. Um deles já foi apontado: uma visão distinta de ambas, ainda que não seja prudente dar o assunto por encerrado. Por outro lado, o cronista pôs em relevo a centralidade do Rio de Janeiro no circuito mercantil atlântico englobando o estuário platino, a Europa e a África, explicitando a importância da produção e do comércio açucareiro e de outros gêneros da terra. Colocou em seus devidos lugares o capitão-mor da cidade, o governador-geral na Bahia e relembrou a malfadada Repartição do Sul.

Antes de chegar ao terceiro momento da Repartição do Sul (1658-1662), do qual se encarregou Salvador Correia de Sá e Benevides, é preciso deixar claro que o seu poder cresceu paulatinamente no Rio de Janeiro. Não somente em termos de riqueza, de influência política ou de capacidade de interferir nos negócios locais, como a historiografia brasileira já tratou longamente e continua a reiterar, mas em relação à sua jurisdição sobre as capitanias do Sul. Se não é propriamente uma vertente original da trajetória de um personagem bem conhecido, é a mais condizente com a discussão em andamento.

Em 1641, Benevides obteve mais um triênio no posto de capitão-mor e governador do Rio de Janeiro, que ocupava desde 1637, devendo exercê-lo "com os poderes e jurisdição e alçada que tem e de que usam os capitães-mores e governadores das outras capitanias do Estado do Brasil”. Seis anos depois, D. João IV, considerando “o quanto convém a meu serviço acudir-se as Capitanias do Sul”, concedeu a Salvador Correia de Sá a patente de "general das capitanias do Rio de Janeiro, Espírito Santo e São Vicente subordinado no tempo da paz ao governador-geral do Estado do Brasil e nas ocasiões de guerra governará sem dependência sua”. Entretanto, em 20 de setembro de 1647, foi encarregado do governo de Angola. ${ }^{17}$

Diante disso, convém dar atenção especial à carta régia de 7 de outubro de 1647. Seu texto complementa o da patente de Salvador Correia de Sá para capitão-general de Angola. Segundo a carta, ele deixaria Lisboa em direção ao Rio de Janeiro para recolher - não sem dificuldades e resistências - as provisões necessárias para socorrer Luanda, ocupada pelos holandeses. ${ }^{18}$ Porém, o documento convida à reflexão sobre outros pontos:

17 ANTT. Registro Geral de Mercês. Mercês da Torre do Tombo. Livro 16, fls. 270v-271. Carta régia de 15/08/1641; Livro 8, fls. 443-443v. Carta régia de 18/01/1647; Livro 15, fls. 455-455v. Carta patente de 20/09/1647 para 0 governo de Angola. Ver também Alencastro (2000:362).

18 Sobre esse episódio, ver o livro clássico de Boxer (1973). Ver também Alencastro (2000:218-238 e 362-363). 
[...] porquanto tenho resoluto que vades em companhia da Armada em direitura ao Rio de Janeiro a fazer nas capitanias de São Vicente, Espírito Santo e naquela praça todos os mantimentos que for possível para socorrer a Armada e alguma cousa que lhe poderá faltar para a tomada de Angola de que vos tenho nomeado governador e para fazer isto com maior brevidade e melhores efeitos. Hei por bem que façais com o título de capitão-mor do Rio de Janeiro com a jurisdição e preeminências com que vos tinha nomeado capitão-mor desta praça antes de serdes declarado governador de Angola. ${ }^{19}$

Uma análise do trecho acima, sobretudo do fragmento grifado, permite certas ponderações. Em primeiro lugar, parece não haver dúvida quanto à decisão régia de fazer Salvador Correia de Sá capitão-mor do Rio de Janeiro, excepcionalmente, para que a autoridade do cargo facilitasse a requisição de mantimentos em São Vicente e no Espírito Santo. Em segundo lugar, conforme o trecho assinalado, ele usufruiria de "jurisdição e preeminências" iguais às previstas na carta régia de 18 de janeiro de 1647, pela qual fora nomeado capitãomor e governador do Rio de Janeiro antes de ser remanejado para Angola. Está explícito na referida carta que o "general das capitanias do Rio de Janeiro, Espírito Santo e São Vicente [estaria] subordinado no tempo da paz ao governador-geral do Estado do Brasil e nas ocasiões de guerra [...] sem dependência sua”. Então, se o tempo era de guerra, durante sua estadia no Rio antes de ir para a África, o general ficou temporariamente isento de sujeição ao governogeral na Bahia.

Quando a provisão de 17 de setembro de 1658 oficializou a Repartição do Sul, Salvador Correia de Sá e Benevides já estava habituado a enfeixar grandes poderes. A ocupação holandesa no Norte contribuiu para isso ao demandar um apoio logístico significativo das capitanias do Sul. O negócio das minas assumiu tamanha importância que, antes mesmo da citada provisão, uma resolução de 10 de julho de 1658 não só garantiu a Salvador Correia de Sá total independência do governador-geral do Brasil como determinou que este colaborasse com o que fosse necessário às buscas. Dois meses depois, o Conselho Ultramarino, do qual Benevides era membro, reforçou que ele deveria governar "independente do Estado do Brasil” para que se lançasse à descoberta e entabulamento das minas de Paranaguá, "que é negócio de muita importância e de que há muitos anos se trata”. Para auxiliá-lo, o Conselho aprovou fornecimentos de pólvora, de munições e de tropas. ${ }^{20}$

No terceiro momento da Repartição do Sul, novamente a questão da centralidade do governo-geral do Estado do Brasil foi levantada. Dessa vez, a impressão vem da historiografia. Ainda que não fosse o seu propósito fazer uma análise pormenorizada daquela divisão administrativa, A. J. R. Russell-Wood reiterou o problema da unidade:

\footnotetext{
Novas unidades administrativas, tais como a Repartição do Sul, [...] fragilizaram o que fora até então percebido como uma única entidade chamada Brasil. [...] A Repartição do Sul, apesar de sua efêmera existência, representou um caso ainda mais grave, porque as capitanias que a constituíam eram essenciais para aquilo que até então era considerado Brasil. [...] O fato desta Repartição ter sido criada em reconhecimento ao serviço de um indivíduo e com a expectativa de que ele pudesse a partir de então prover uma liderança mais dinâmica, representou uma afronta ao governador-geral em Salvador. Tamanha fragmentação tornava difuso aquilo que havia se constituído na linha direta de autoridade entre o rei, os seus conselheiros, e o governador-geral em Salvador. Na colônia, de forma correspondente, a centralização da autoridade na pessoa do governador-geral encontrava-se enfraquecida. (Russell-Wood, 1998:231-232)
}

19 ANTT. Registro Geral de Mercês. Mercês da Torre do Tombo. Livro 15, fl. 461. Carta régia de 07/10/1647. Grifo nosso.

20 Arquivo Histórico Ultramarino. Coleção Castro e Almeida. Rio de Janeiro, caixa 5, docs. 781-782. Projeto Resgate. Rio de Janeiro (avulsos). AHU ACL CU 017, Cx. 3, D. 320. ANTT. Chancelaria de D. Afonso VI. Livro 23, fls. 111v-112. Carta patente de 17/09/1758 nomeando Salvador Correia de Sá governador de "todas as capitanias do Sul [...] para melhor expediente do negócio das minas a que vai e isto sem nenhuma dependência do governador e capitão-general do Estado do Brasil". Há indicações de que sua posse não foi imediata porque Salvador de Sá se dedicou a "preparar uma expedição ao Espírito Santo em busca da famosa e lendária Serra das Esmeraldas” (Cf. Coaracy, 1955:146-148). 
Do ponto de vista de Russell-Wood, a Repartição do Sul comprometia o princípio da unidade da administração colonial preconizada na criação do Governo-geral. Ficou subjacente, entretanto, certo sentido na separação das capitanias de baixo. Afinal, em meados do século XVII, o Rio de Janeiro tinha "a primazia política e, sobretudo, econômica” no Sul da América, inclusive, por conta da produção do açúcar (Cf. Sampaio, 2003:65-67). Mas a conclusão de que a Repartição foi "criada em reconhecimento ao serviço de um indivíduo e com a expectativa de que ele pudesse a partir de então prover uma liderança mais dinâmica" - uma alusão a Salvador Correia de Sá - e que isso "representou uma afronta ao governadorgeral em Salvador” não é original. D. Diogo de Meneses percebeu isso com a vinda de D. Francisco de Sousa.

Detalhar os motivos da revogação da Repartição do Sul seria demasiado extenso. Podese dizer que a frustração quanto aos achados minerais e os tumultos no Rio de Janeiro, palco de uma rebelião de cunho político relacionada à fiscalidade - a Revolta da Cachaça (1660-1661 $)^{21}$ - influenciaram a decisão régia de reunificar a administração do Estado do Brasil em Salvador. No final de sua gestão, o governador-geral Francisco Barreto de Meneses (1657-1663) começou a colocar ordem nos negócios. Impôs limites à alçada e à jurisdição de oficiais régios e, para tanto, correspondeu-se com seus subalternos, como Pedro de Melo, governador do Rio de Janeiro (1662-1666). Nesse caso, as medidas tinham o propósito de extirpar abusos cometidos por Salvador Correia de Sá e Benevides. ${ }^{22}$ O objetivo maior, no entanto, era restaurar a unidade e a centralidade do governo-geral e a autoridade do seu titular. Essa tarefa coube ao sucessor de Francisco Barreto de Meneses, D. Vasco de Mascarenhas, $1^{\mathrm{o}}$ conde de Óbidos, que veio com o título de vice-rei (1663-1667) e "pela sua patente foi restabelecida a unidade de governo no Brasil, sendo novamente sujeita à jurisdição da Bahia a capitania do Rio de Janeiro". ${ }^{23}$

Para dar prosseguimento à reorganização administrativa do Estado do Brasil, serviu de base o Regimento do $1^{\circ}$ conde de Óbidos, de 1663. Vivaldo Coaracy apontou que o documento era composto de treze artigos, extinguia os poderes usufruídos por Salvador Correia de Sá e Benevides e restringia atribuições conferidas aos governantes do Rio de Janeiro por Mem de Sá. ${ }^{24}$ Coaracy aparentemente confundiu-se sobre o alcance do Regimento, o que não exclui a possibilidade de adaptações às peculiaridades de cada capitania, disseminadas na correspondência oficial. Em trabalho mais recente e aprofundado, Francisco Cosentino atentou para o fato de que o Regimento de 1663 procurou atalhar "autonomias" usufruídas por capitanias como Rio de Janeiro e Pernambuco em reforço da autoridade do governadorgeral (Cosentino, 2009:257-258).

Para encerrar, é oportuno refletir sobre certas palavras de Américo Jacobina Lacombe, para quem a fragmentação da autoridade do governador-geral do Brasil era, ao mesmo tempo, a manifestação da capacidade de acomodação e de adaptação da estrutura da administração colonial a um meio geográfico centrifugador e de "um espírito prático que transparece nos atos da Coroa" (Lacombe, 1967:29-30). Na prática, como se viu, não foi tão simples conciliar as expectativas da metrópole, o exercício (e a expressão) do poder e a complexa dinâmica da colonização.

21 Sobre esse episódio ver, por exemplo, Caetano (2009).

22 Cf. Documentos Históricos da Biblioteca Nacional [DHBN]. Rio de Janeiro, vol. 5, p. 164-165.

23 Cf. DHBN, vol. 6, p. 31. Carta de 07/04/1664.

24 Sobre a nomeação do vice-rei e o Regimento para os governadores do Rio de Janeiro ver Coaracy (1944:167). 0 vice-rei afirmou que o Regimento era para todos os capitães-mores do Brasil (Cf. DHBN, vol. 5, p. 467-469). 


\section{Considerações finais}

Celebrações são comumente momentos de balanço. E eles podem ser longos, repetitivos e, ainda assim, não contemplarem todos os aspectos de uma questão, especialmente uma antiga polêmica como a da fundação de São Sebastião do Rio de Janeiro. Sobre a dificuldade de diferenciar cidade e capitania, nem as autoridades da época souberam fazê-lo nos seus primórdios. As cartas de nomeação dos primeiros governantes confirmam isso. Mas esse não foi propriamente um traço exclusivo do Rio. Não é incomum encontrar na documentação colonial menções à cidade do Salvador ou à cidade da Bahia como a capital do Estado do Brasil.

As lacunas, imprecisões e equívocos se estendem à história da Repartição do Sul, em que a ideia de uma capitania do Rio de Janeiro aparece um pouco mais clara, a começar pelas patentes dos seus titulares. A Repartição do Sul se entrelaça com o problema da "cidade-capitania”, sobretudo, nas duas primeiras vezes em que se apresentou como solução administrativa. Daí a conclusão: o período que vai da fundação da cidade e da capitania ao início do século XVII, pouco mais ou menos, é um verdadeiro cipoal pronto a enredar os estudiosos.

O estudo da Repartição do Sul nos séculos XVI e XVII está sendo retomado atualmente. Nessa direção, o trabalho de Mônica da Silva Ribeiro evidencia esse interesse renovado pelo tema da divisão do governo do Brasil. Fica claro, inclusive, que o assunto não se esgota na própria estratégia de divisão. Isso pode ser demonstrado pelo processo de construção da centralidade do Rio de Janeiro a partir de meados do século XVII, devido à sua posição estratégica no comércio Atlântico e com a região do Prata, bem como em relação à atividade mineradora. ${ }^{25}$ Essa situação se consolidou no decorrer do século XVIII até a transferência da capital do Estado do Brasil de Salvador para o Rio de Janeiro, em 1763.

Por tudo isso, muito mais do que essas notas poderiam atender ao retomar problemas de interpretação histórica, exercitar um pouco a crítica historiográfica e, quem sabe, apontar caminhos para discussão, os temas aqui tratados apontam, além do especial cuidado no tratamento e no cotejo de fontes e de obras, para a continuidade do interesse - retomado pelos historiadores, sobretudo, nas duas últimas décadas - pelo estudo da história políticoadministrativa do Brasil colonial.

\section{Referências bibliográficas}

ABREU, Maurício de Almeida. Geografia histórica do Rio de Janeiro (1502-1700). Rio de Janeiro: Andrea Jakobsson Estúdio \& Prefeitura do Município do Rio de Janeiro, 2010.

ALENCASTRO, Luiz Felipe de. O trato dos viventes: formação do Brasil no Atlântico Sul (séculos XVI e XVII). São Paulo: Companhia das Letras, 2000.

25 Sobre essa questão ver o Capítulo 4 da tese de Mônica da Silva Ribeiro, em especial 0 tópico "0 Rio de Janeiro como cabeça do centro-sul da América portuguesa" (Ribeiro, 2010:165-189). 
ALMEIDA, Maria Regina Celestino de. Metamorfoses indígenas: identidade e cultura nas aldeias coloniais do Rio de Janeiro. Rio de Janeiro: Arquivo Nacional, 2003.

BOXER, Charles Ralph. Salvador de Sá e a luta pelo Brasil e Angola, 1602-1686. Trad. Olivério M. de Oliveira Pinto. São Paulo: Companhia Editora Nacional, 1973.

BRANDÃO, Ambrósio Fernandes. Diálogos das grandezas do Brasil. Introdução de Capistrano de Abreu; Notas de Rodolfo Garcia. Rio de Janeiro: Of. Industrial Gráfica, 1930.

CAETANO, Antônio Filipe Pereira. Entre a sombra e o sol: a Revolta da Cachaça e a crise política fluminense. Maceió: Q Gráfica, 2009.

CAVALCANTI, Nireu de Oliveira. O Rio de Janeiro setecentista: a vida e a construção da cidade da invasão francesa até a chegada da Corte. Rio de Janeiro: Jorge Zahar Editor, 2004.

COARACY, Vivaldo. O Rio de Janeiro no século 17. Rio de Janeiro: Livraria José Olympio Editora, 1944.

. Memórias da cidade do Rio de Janeiro. Rio de Janeiro: Livraria José Olympio Editora, 1955.

COSENTINO, Francisco Carlos. Governadores Gerais do Brasil (séculos XVI-XVII): ofício, regimentos, governação e trajetórias. São Paulo: Annablume; Belo Horizonte: Fapemig, 2009.

DAHER, Andrea. O Brasil francês: as singularidades da França Equinocial (1612-1615). Rio de Janeiro: Civilização Brasileira, 2007.

DOURADO, Mecenas. A cidade do Rio de Janeiro: sua fundação em 1567. Rio de Janeiro: Livraria São José, 1965.

ENDERS, Armelle. A história do Rio de Janeiro. Trad. Joana Angélica D’Ávila Melo. 2. ed. Rio de Janeiro: Gryphus, 2008.

FRAGOSO, João. A nobreza da República: notas sobre a formação da primeira elite senhorial do Rio de Janeiro (séculos XVI e XVII). Topoi - Revista de História. Rio de Janeiro, n. 1, p. 45-122, 2000.

FURTADO, Júnia Ferreira. O Distrito dos Diamantes: uma terra de estrelas. In: RESENDE, Maria Efigênia Lage de; VILLALTA, Luiz Carlos (orgs.). História de Minas Gerais - As Minas Setecentistas. Belo Horizonte: Autêntica, 2007. vol. 1. p. 303-320.

GANDAVO, Pero de Magalhães. Tratado da Terra do Brasil. Brasília: Edições do Senado Federal, 2008.

GOUVÊA, Maria de Fátima Silva. Governo Geral. In: VAINFAS, Ronaldo (dir.). Dicionário do Brasil colonial (1500-1808). Rio de Janeiro: Objetiva, 2000.

GUIMARÃES, Lúcia Maria Paschoal. Francisco Adolfo de Varnhagen - História Geral do Brasil. In: MOTA, Lourenço Dantas (org.). Introdução ao Brasil. Um banquete no trópico. São Paulo: Editora SENAC, 2001. vol. 2. p. 75-96.

IGLÉSIAS, Francisco. Historiadores do Brasil: capítulos de historiografia brasileira. Rio de Janeiro: Nova Fronteira; Belo Horizonte: Ed. UFMG/IPEA, 2000.

KNAUSS DE MENDONÇA, Paulo. O Rio de Janeiro da pacificação: franceses e portugueses na disputa colonial. Rio de Janeiro: Secretaria Municipal de Cultura, Turismo e Esportes; Departamento Geral de Documentação e Informação Cultural; Divisão de Editoração, 1991.

18 - Cadernos do Desenvolvimento Fluminense, Rio de Janeiro, N.7, pp. 5 - 20, jan./jun. 2015 
; SANTOS, Fabiano Vilaça dos. "O Roteiro dos Sete Capitães: história do documento". In: GABRIEL, Adelmo Henrique D.; LUZ, Margareth da (orgs.); FREITAS, Carlos Roberto B.; SANTOS, Fabiano Vilaça dos; KNAUSS, Paulo (transcrição e edição); SOFFIATI, Arthur (notas). Roteiro dos Sete Capitães: documentos e ensaios. Macaé: Funemac Livros, 2012.

LACOMBE, Américo Jacobina. A muito leal e heroica cidade de São Sebastião do Rio de Janeiro. Revista do Instituto Histórico e Geográfico Brasileiro. Rio de Janeiro, vol. 276, p. 2340, 1967.

LOBO, Eulália Maria Lahmeyer. História do Rio de Janeiro (do capital comercial ao capital industrial e financeiro). Rio de Janeiro: IBMEC, 1978. vol. 1.

MACHADO, Humberto Fernandes. Rio de Janeiro, capitania do. In: SILVA, Maria Beatriz Nizza da (coord.). Dicionário da história da colonização portuguesa no Brasil. Lisboa: Editorial Verbo, 1994.

MARIZ, Vasco; PROVENÇAL, Lucien. Villegagnon e a França Antártica: uma reavaliação. Rio de Janeiro: Nova Fronteira, 1999.

NEVES, Guilherme Pereira das. Rocha Pita. In: VAINFAS, Ronaldo (dir.). Dicionário do Brasil colonial (1500-1808). Rio de Janeiro: Objetiva, 2000.

PAIVA, José Pedro. Os bispos de Portugal e do Império, 1495-1777. Coimbra: Imprensa da Universidade de Coimbra, 2006.

PAULA, João Antonio de. A mineração de ouro em Minas Gerais do século XVIII. In: RESENDE, Maria Efigênia Lage de; VILLALTA, Luiz Carlos (orgs.). História de Minas Gerais - As Minas Setecentistas. Belo Horizonte: Autêntica, 2007. vol. 1. p. 279-301.

PINHEIRO, Joaquim Caetano Fernandes (cônego). A França Antártica. Revista do Instituto Histórico e Geográfico Brasileiro. Rio de Janeiro, vol. 22, p. 3-134, 1859.

PITA, Sebastião da Rocha. História da América portuguesa, desde o ano do seu descobrimento em 1500 até ao de 1724. Belo Horizonte: Itatiaia; São Paulo: EDUSP, 1976.

RIBEIRO, Mônica da Silva. Divisão governativa do Estado do Brasil e a Repartição do Sul. In: XII ENCONTRO REGIONAL DE HISTÓRIA DA ANPUH-RJ - Usos do passado. Niterói, Universidade Federal Fluminense, 2006. Anais..., p. 1-9. Disponível em: www.rj.anpuh.org. Acesso em: 10/02/2014.

- "Se faz preciso misturar o agro com o doce": a administração de Gomes Freire de Andrada, Rio de Janeiro e Centro-Sul da América portuguesa (1748-1763). Tese de Doutorado, UFF/PPGH, 2010.

RUSSELL-WOOD, A. J. R. Centros e periferias no mundo luso-brasileiro, 1500-1808. Trad. Maria de Fátima Silva Gouvêa. Revista Brasileira de História. São Paulo, vol. 18, n. 36, p. 187-249, 1998.

SALGADO, Graça (coord.). Fiscais e meirinhos: a administração no Brasil colonial. 2. ed. Rio de Janeiro: Nova Fronteira, 1990.

SALVADOR, Frei Vicente do. História do Brazil. Curitiba: Juruá Editora, 2008.

SAMPAIO, Antônio Carlos Jucá de. Na encruzilhada do império: hierarquias sociais e 
conjunturas econômicas no Rio de Janeiro (c.1650-c.1750). Rio de Janeiro: Arquivo Nacional, 2003.

SANCHES, Marcos Guimarães. O Rio de Janeiro e a "Repartição do Sul” no período filipino: consolidação e expansão da colonização. Revista do Instituto Histórico e Geográfico Brasileiro. Rio de Janeiro, vol. 166, n. 426, p. 105-146, 2005.

SERRÃO, Joaquim Veríssimo. O Rio de Janeiro no século XVI. Lisboa: Comissão Nacional das Comemorações do IV Centenário do Rio de Janeiro, 1965. 2 vols.

O tempo dos Filipes em Portugal e no Brasil (1580-1668). 2. ed. Lisboa: Edições Colibri, 2004.

VILARDAGA, José Carlos. As controvertidas minas de São Paulo (1550-1650). Varia Historia. Belo Horizonte, vol. 29, n. 51, p. 795-815, set./dez. 2013.

WEHLING, Arno. "Repartição do Sul”. In: SILVA, Maria Beatriz Nizza da (coord). Dicionário da história da colonização portuguesa no Brasil. Lisboa: Editorial Verbo, 1994.

WEHLING, Arno; WEHLING, Maria José C. M. Formação do Brasil colonial. 4. ed. Rio de Janeiro: Nova Fronteira, 2005.

copyright (C) Cccreative Santos 